\title{
Ultrasound imaging of acute scrotum: Pictorial review with etiological correlation
}

Anitha Mandava, M.B.B.S., D.M.R.D., D.N.B.

Veeraiah Koppula, M.B.B.S., D.N.B.

Rohit Yalamanchili, M.B.B.S, M.D.

Dilip Yadav, MBBS, D.N.B.

Juluri Rakesh, M.B.B.S, M.D.

From Department of Radiodiagnosis, Basavatarakam Indo American Cancer Hospital \& Research Institute, Telangana, India.

Address correspondence to A.M. (e-mail: kanisri@gmail.com)

\section{Abstract}

High resolution ultrasound with color Doppler is the first-line imaging investigation in the evaluation of acute scrotum. It plays a crucial role in distinguishing urological emergencies necessitating immediate surgical exploration from those that can be managed conservatively. Acute scrotal pathologies can involve the scrotal sac or its contents like testis, epididymis and testicular appendages and could range from benign, self-limiting conditions to emergencies. In this pictorial essay, we briefly review the ultrasonographic technique, scrotal anatomy and characteristic imaging features of various pathologies presented as acute scrotum.

Keywords: Acute scrotum, Testis, High resolution ultrasound, Color doppler. 


\section{Introduction}

Acute scrotum is defined as scrotal pain, with or without swelling and redness, of acute onset[1,2]. Ultrasonography (US) with high resolution ultrasound probe and color Doppler is the primary imaging modality in the evaluation of acute scrotal pathology. In this article, we review and discuss sonographic appearances of both common and uncommon conditions presenting with acute scrotum.

The etiology of acute painful scrotum is varied, ranging from benign and selflimiting conditions to those that are medical and surgical emergencies (Table 1). The commonly encountered cases of acute scrotum in clinical practices are acute epididymo-orchitis, torsion of testis or testicular appendages and traumatic injuries[3]. Prompt imaging workup and rapid diagnosis are essential to avoid adverse outcomes as few of these conditions need immediate surgical and urologic intervention[4]. US imaging of acute scrotum is quick, cost effective and accurate with almost $100 \%$ sensitivity in the detection and differentiation of intra- and extratesticular diseases[3-7].

US of scrotum is performed with the patient lying down in the supine position while supporting the scrotum by positioning a folded towel or sheet between the legs. Linear array (4-13 MHz) and convex curved array (1-8 MHz) transducers are used for scrotal and abdominal ultrasonography, respectively. Transverse and sagittal images of bilateral testis and epididymis are obtained in gray-scale and color Doppler modes. The size, echogenicity, and blood flow of each testis and epididymis are compared to the contralateral side $[8,9]$. The spermatic cord and the relevant extratesticular structures are also evaluated in suspicious cases of testicular torsion[6,8]. Doppler sonography (spectral and color/power Doppler imaging) is used with low-flow detection settings in all cases of acute scrotal pain[7]. 
Table 1. Differential diagnosis of acute scrotum according to etiology.

\begin{tabular}{ll}
\multicolumn{1}{c}{ Etiology } & \multicolumn{1}{c}{ Possible diagnoses } \\
Inflammation, Infections & Scrotum: Scrotal wall cellulitis, Pyocele \\
& Perineum: Fournier's gangrene \\
& Testis and epididymis: Acute epididymo-orchitis, \\
& Acute epididymitis, Acute orchitis, Emphysematous \\
& epididymo- orchitis, Testicular abscess \\
& Testis: Testicular torsion, \\
& Testicular appendages: Torsion of testicular appendages. \\
Vascular Causes & Venous plexus: Varicocele \\
& Testis: Contusion, laceration, Testicular \\
& fracture, Testicular rupture, hematocele, hematoma. \\
Trauma & Scrotum: Acute hydrocele, hematocele, \\
& hematoma. \\
& Testis: Primary: Germ cell tumor (seminoma), \\
& Nonseminomatous germ cell tumor, Lymphoma \\
& Secondary: Lymphoma, Leukaemia, Metastases \\
Tumors & Scrotum: Extratesticular malignancy \\
& Obstructed/ strangulated inguinoscrotal hernias, Spermatic cord \\
& hydrocele or cyst
\end{tabular}

Normal sonographic scrotal anatomy: The scrotum has two testes, one in each hemiscrotum separated by a septum. The scrotal wall is $2-8 \mathrm{~mm}$ in thickness[10]. Tunica vaginalis is derived from the processus vaginalis of the peritoneum with the inner visceral layer enveloping most of the testis and epididymis, and the outer parietal layer lining the internal spermatic fascia of the scrotal wall. Hydroceles or other fluid collections (eg, blood or pus) may accumulate in the potential space between these layers. The normal adult testis is ovoid and approximately measures $5 \times 3 \times 3 \mathrm{~cm}$ with homogeneous, intermediate echotexture[11]. Epididymal head and tail are at the superior and inferior poles of the testis, respectively and are isoechoic to testis. The testicular appendages are the remnants of embryonic ducts and the only testicular appendages seen on ultrasound are the appendix testis and the appendix epididymis. The scrotum is supplied by the external pudendal, internal pudendal and the cremasteric arteries and the venous drainage follows the arterial supply. The testes are supplied by the testicular arteries, branches of 
the abdominal aorta and the venous drainage is via the pampiniform plexus of draining veins into the testicular veins that drain into the inferior vena cava on the right side and the renal vein on the left side[12].

Inflammation and infections: Scrotal wall cellulitis is due to an acute bacterial infection of the skin and subcutaneous tissues. It can spread quickly and in untreated or incompletely treated cases it may progress to form scrotal abscess. HRUS in cellulitis shows an increase in the thickness of the scrotal wall with anechoic to hypoechoic areas in the skin and subcutaneous tissues of scrotal wall (Figure 1A) [13].

Fournier's gangrene is a life-threatening necrotizing fasciitis of the perineal, genital and perianal regions with a high mortality rate. It occurs more commonly in males, especially in diabetics, alcoholics and those who are immunocompromised. US may show the thickening of the subcutaneous tissues and fascia of the perineum with abnormal fluid and air collections within these tissues (Figure 1B). Castleberg et al have proposed a mnemonic "STAFF" for rapidly diagnosing Fournier's gangrene by using bedside ultrasound evaluation for Subcutaneous thickening, Air, and Fascial Fluid (STAFF)[14].

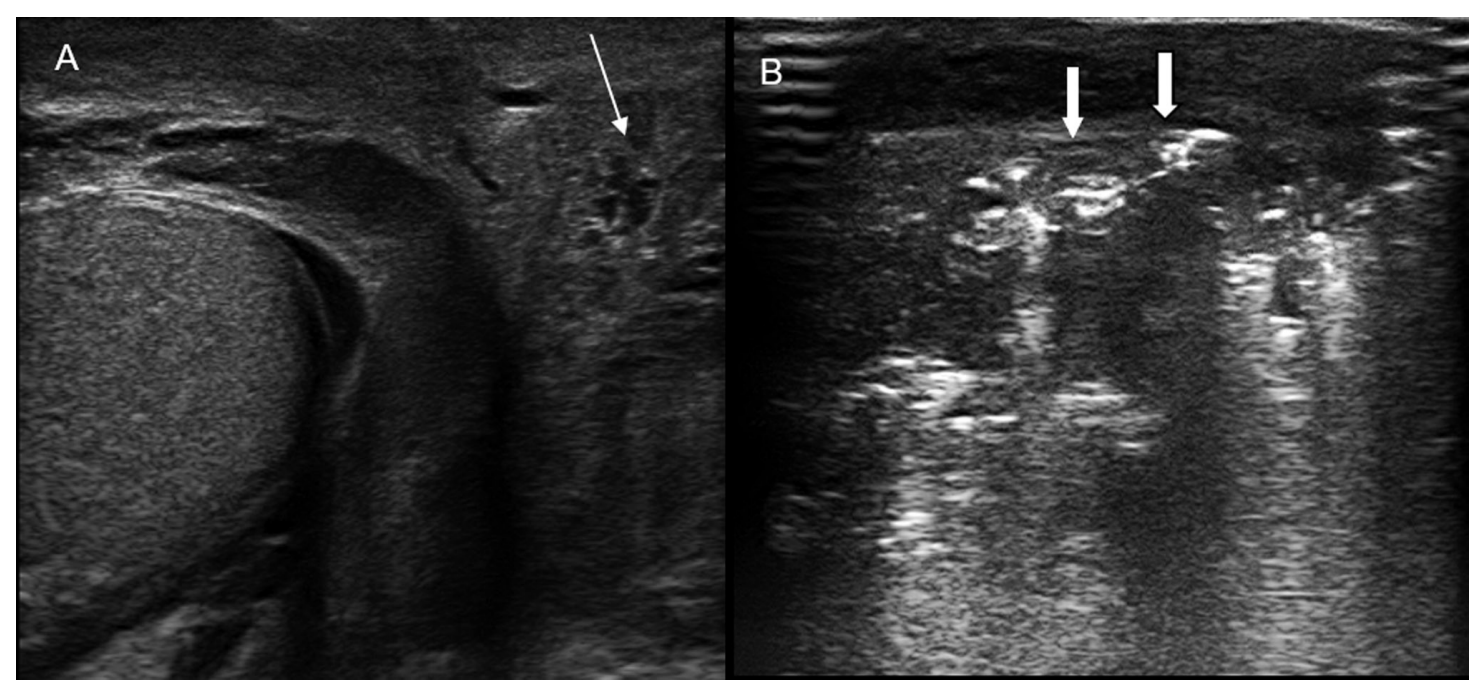

Figure 1. (A) Scrotal wall cellulitis: Scrotal wall thickening with anechoic to hypoechoic areas (thin arrow). (B) Fournier's gangrene: Subcutaneous gas within the scrotal wall seen as numerous discrete hyperechoic foci with reverberation artefacts (thick arrows), the sonographic hallmark. 
Epididymo-orchitis is the most common cause of acute scrotum in boys and adults and, if left untreated, may lead to abscess formation and testicular infarction $[4,7,13]$. US features include enlargement of the epididymis, testis or both with decreased echogenicity, reactive hydrocele and scrotal wall thickening. The sonographic hallmark of epididymo-orchitis is the highly increased vascularity of epididymis and testis seen on color Doppler imaging (Figure 2A,B). Retrograde bacterial infection from a lower urinary tract infection is the usual cause of epididymo-orchitis, but rarely, it could also be from a viral infection. Infections can be limited to only epididymis leading to acute epididymitis, the epididymal head being the most commonly affected region (Figure 3). Isolated orchitis without epididymitis is rare, but can occur in mumps infection.

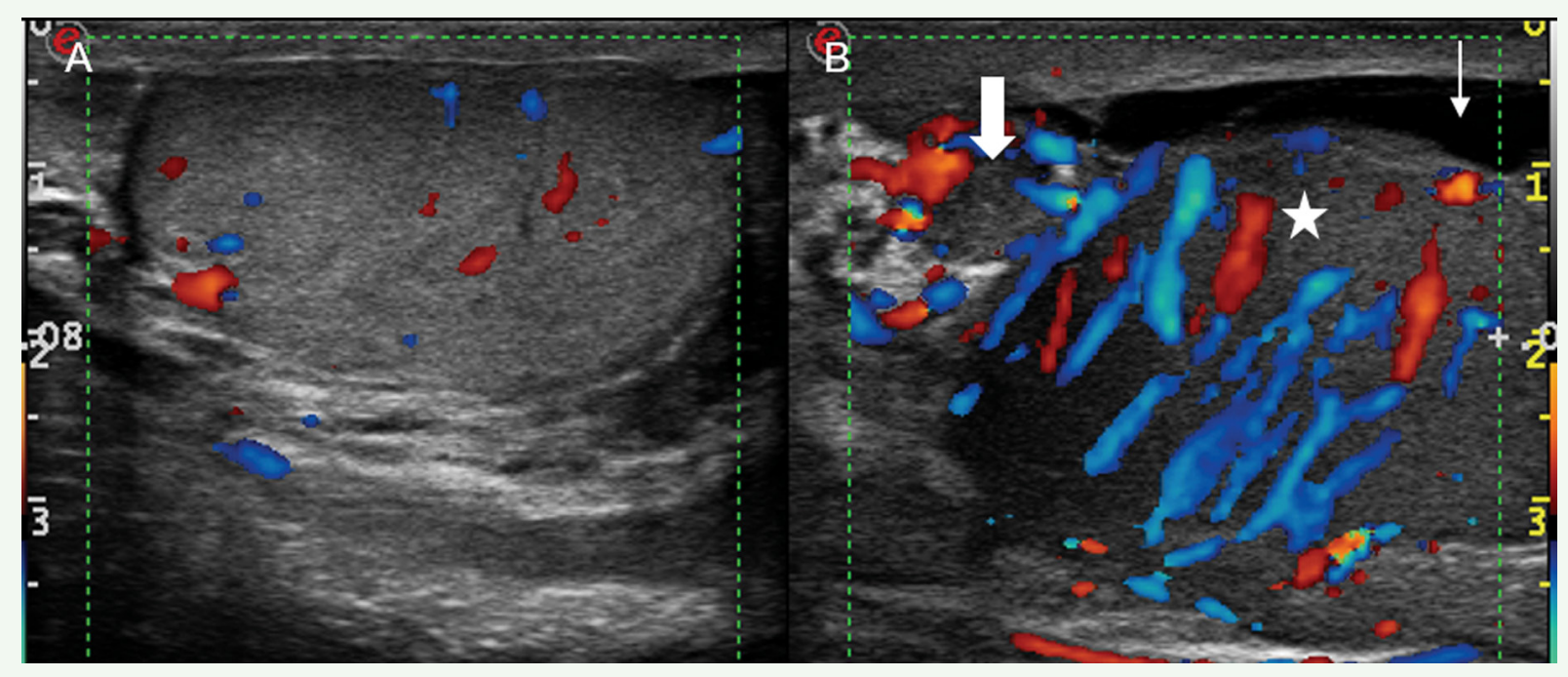

Figure 2. Acute epididymo-orchitis: Split screen US shows (A) normal right testis (B) enlarged hypoechoic left testis $\left(^{*}\right)$ and epididymis (thick arrow) with marked hyperemia and reactive hydrocele (thin arrow). 


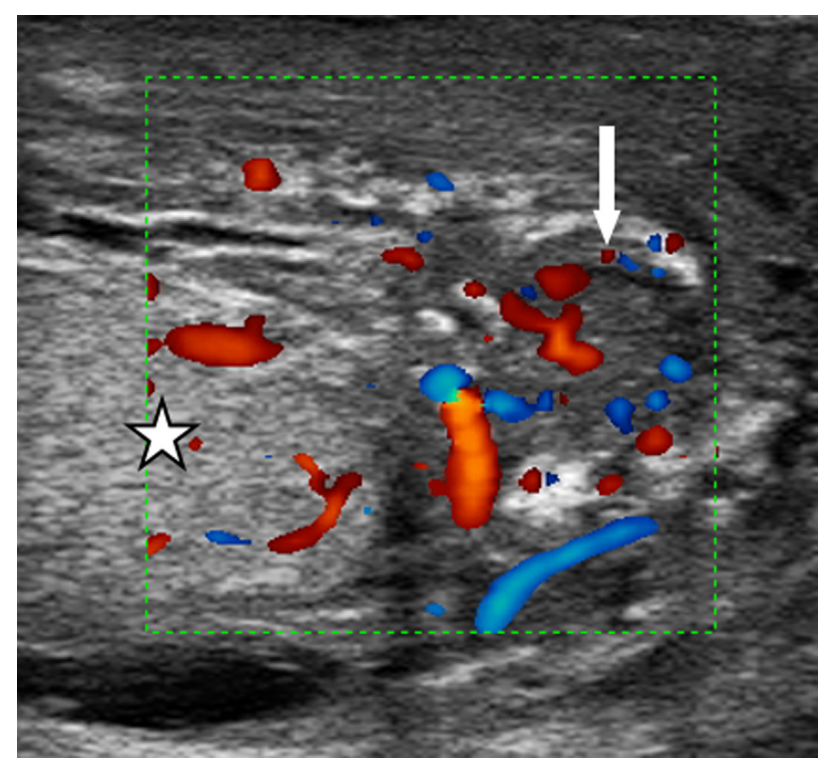

Figure 3. Acute epididymitis: Enlarged epididymis (thick arrow) with variable echotexture and increased blood flow.

Emphysematous epididymo-orchitis is an uncommon, acute inflammatory process of epididymis and testis, characterized by the presence of air within the tissue. It is a rare urologic emergency that needs prompt diagnosis and treatment. US shows intratesticular air as focal bright hyperechoic areas with distal acoustic shadowing that can be moved or displaced by transducer pressure (Figure 4)[15]. Intratesticular abscess and pyocele develop secondary to trauma and testicular infarction or can occur in advanced or untreated cases of epididymo-orchitis $[13,16]$ US features of testicular abscess include intratesticular areas of complex hypoechogenicity showing low-level internal echoes, shaggy irregular walls and peripheral hyperaemic margins on color Doppler (Figure 5A). Focal orchitis or abscess may be difficult to differentiate from testicular tumour but associated epididymal involvement and scrotal skin thickening are suggestive of infection rather than tumour[16]. Rupture of an intratesticular abscess into the space between the layers of the tunica vaginalis results in pyocele. Pyocele is a surgical emergency as it can progress rapidly causing testicular damage, sepsis or complications like Fournier's gangrene. Early diagnosis, broad spectrum antibiotics, surgical drainage and in a few cases orchidectomy are indicated in the management. Pyoceles on US may be seen as complex anechoic intrascrotal collections with internal echoes, septations, loculations and skin thickening (Figure 5B). 


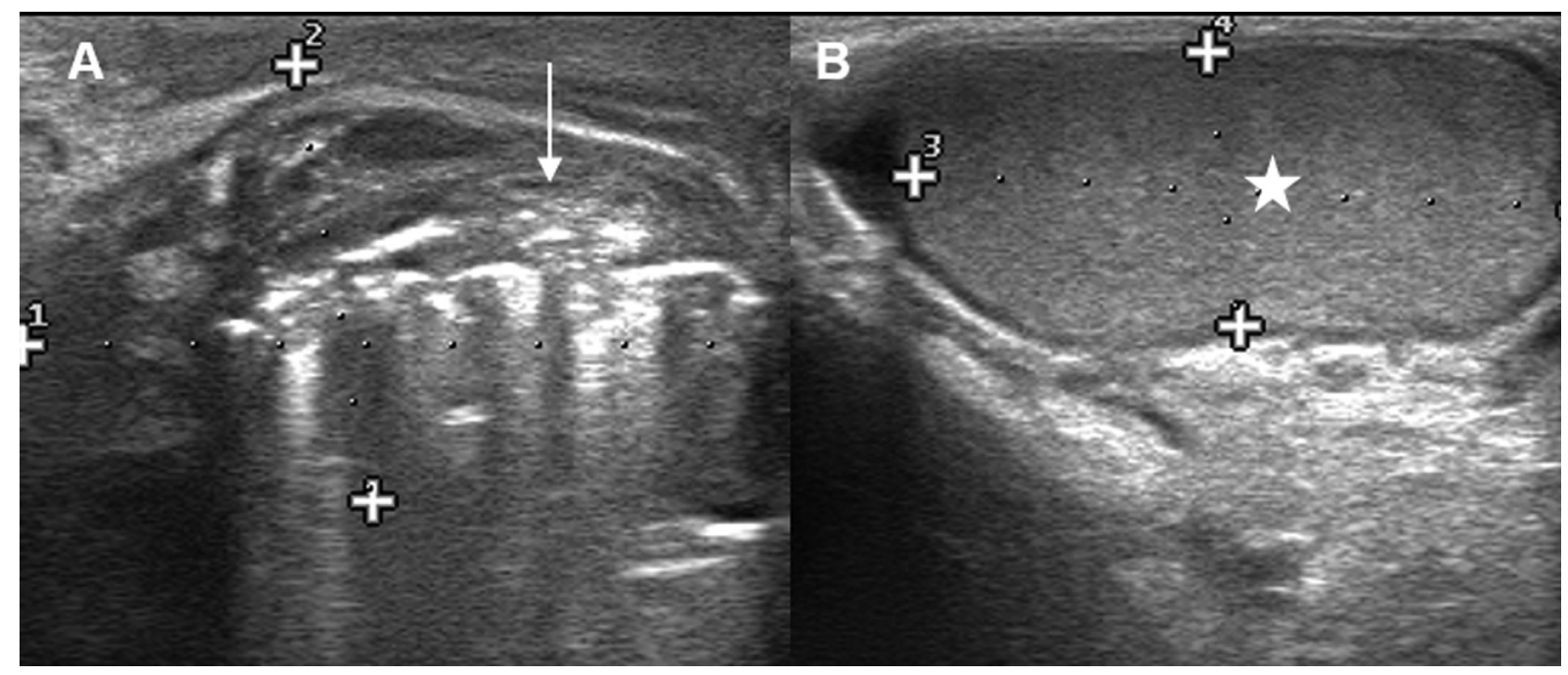

Figure 4. Emphysematous epididymo orchitis: Split screen US shows (A) normal left testis $\left(^{*}\right)$ (B) enlarged, ill-defined right testis with multiple linear and punctate bright, highly reflective hyperechoic foci (arrow).

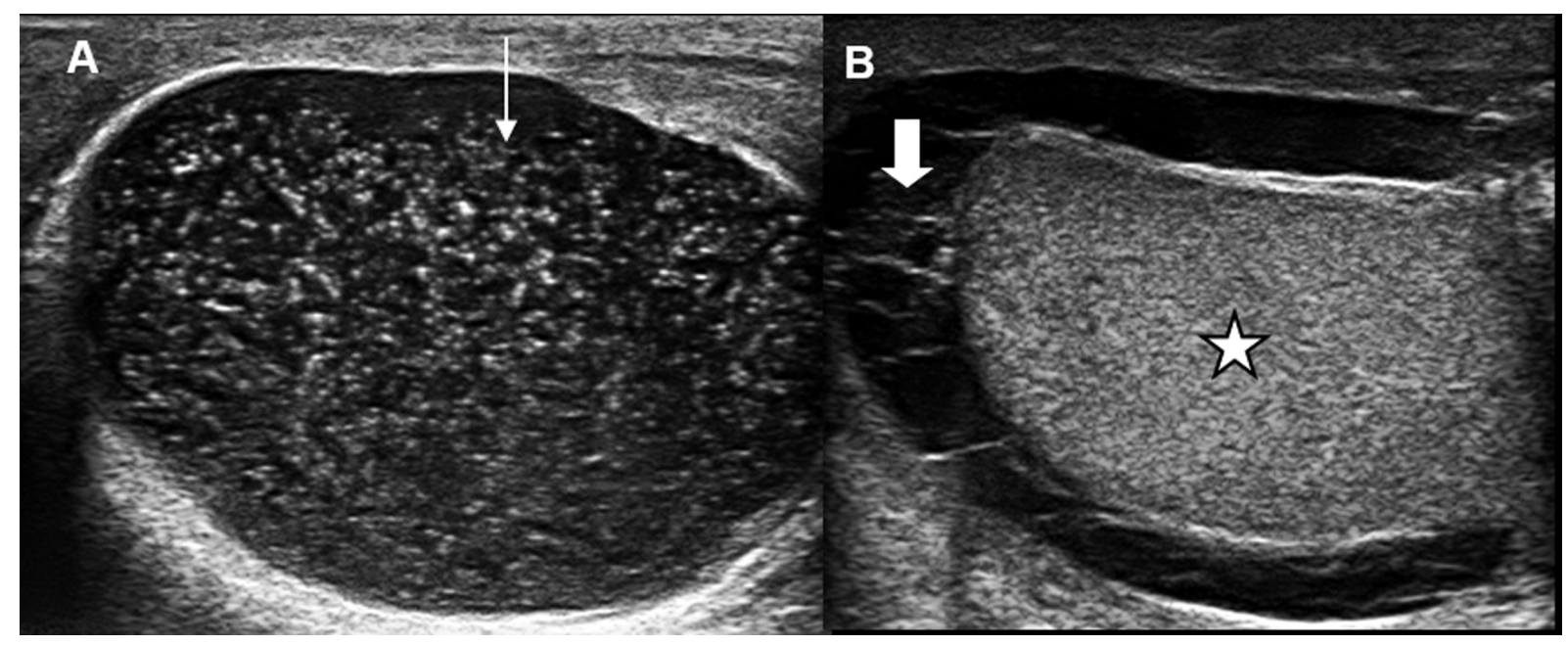

Figure 5. (A) Intratesticular abscess: Enlarged testis with low-level intratesticular internal echoes (thin arrow). (B) Pyocele: Free fluid in the scrotum with newly developed septations, echogenic debris and thickened scrotal skin (thick arrow) and normal testis $\left(^{*}\right.$ ). 
Vascular Causes: Testicular torsion can occur at any age, but is most common in young adolescents and it is an emergency that needs immediate surgical exploration to salvage the testis[2,6]. US features and the testicular salvage rate depend on the duration of ischemia and the degree of torsion that can range from $180^{\circ}$ to $720^{\circ}$ or more[9]. Acute testicular torsion with a viable testis can be normal on HRUS; hence, absence of detectable blood flow in the testis on colour Doppler US is essential to confirm testicular torsion (Figure 6A)[9]. As ischemia progresses, the testis becomes enlarged and hypoechoic. Later, the testis may develop heterogeneous echotexture secondary to haemorrhage and infarction and these findings may suggest nonviability[4]. US of spermatic cord cranial to the testis at the site of torsion can show an oedematous round or ovoid intrascrotal cord with the epididymal head wrapped around it, appearing as a whirlpool, or a doughnut[6]. The real-time whirlpool sign is seen on gray scale as well as color Doppler imaging (Figure 6B,C) in both complete and incomplete torsions and it is the most definitive sign of torsion with $100 \%$ specificity and sensitivity[6].

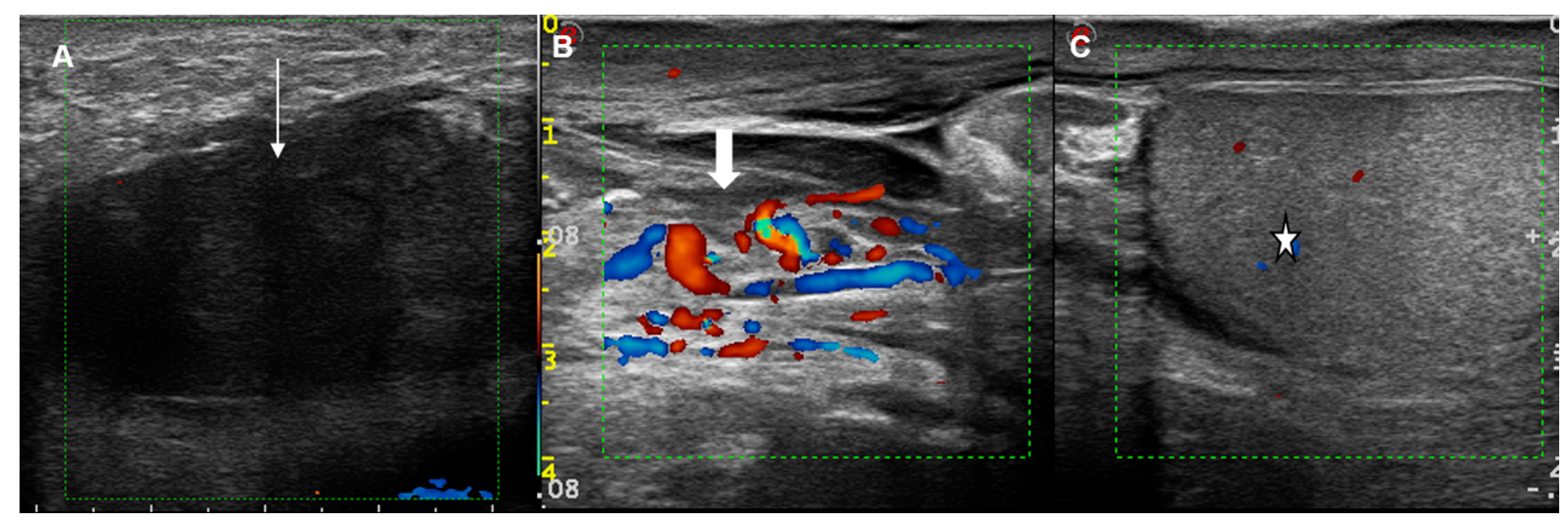

Figure 6. (A) Acute torsion: Hypoechoic testis with completely absent vascularity on color Doppler (thin arrow). (B,C) Split screen color Doppler US shows "Whirl pool" sign of testicular torsion due to the twisting of spermatic cord (thick arrow) and avascular testis $\left(^{*}\right)$. 
Torsion of testicular appendages can present as the acute scrotum and the role of US in this condition is to exclude testicular torsion and acute epididymoorchitis[9]. US appearance of torsion of the appendages of the testes is variable. The twisted appendage may be isoechoic, hypoechoic, or hyperechoic to the testis and epididymis with increased vascular flow around it while the adjacent testis or epididymis show normal vascularity (Figure 7 ) $[3,9]$.

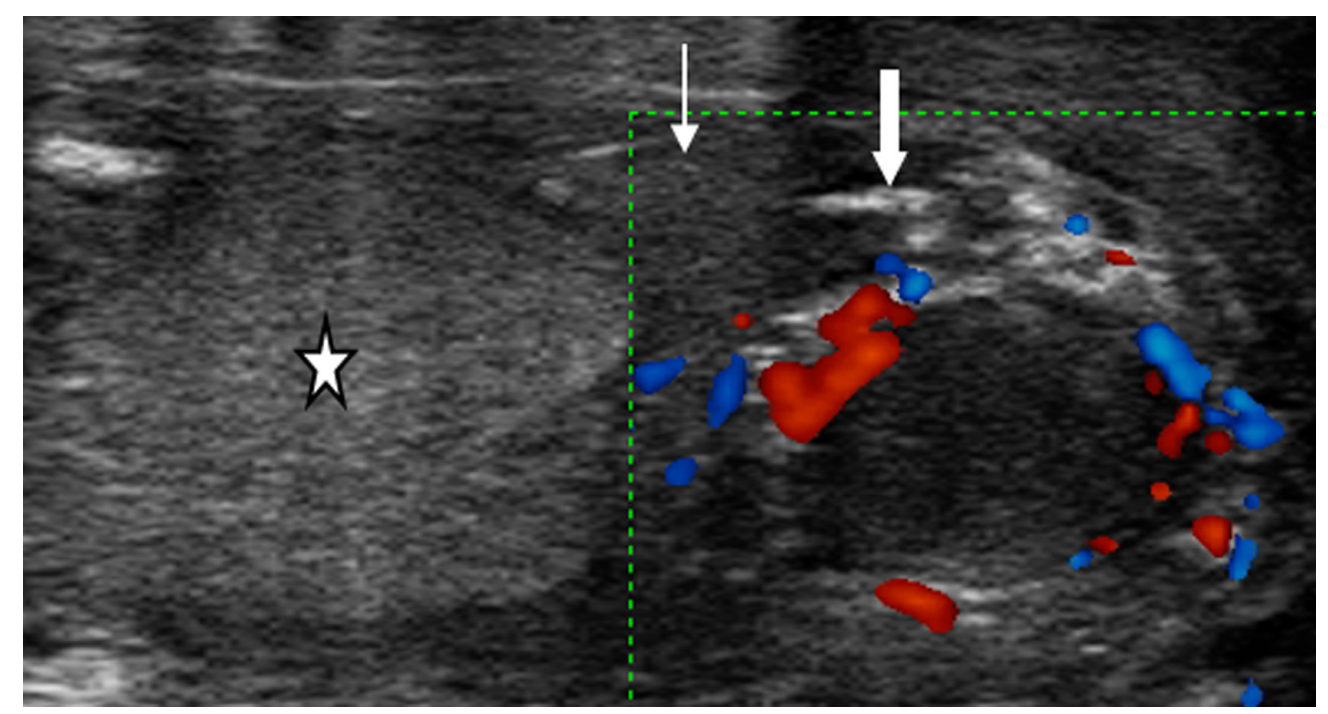

Figure 7. Appendiceal torsion: Torsed testicular appendage seen as a circular mass of variable echogenicity with increased peripheral flow around it (thick arrow). Normal testis $\left(^{*}\right)$ and epididymis (thin arrow).

Varicoceles are abnormally dilated, tortuous veins of the pampiniform plexus. Most often they are asymptomatic or cause dull pain and discomfort but rarely can they mimic the pain of acute testicular torsion. Color Doppler US is nearly $100 \%$ sensitive and specific in the diagnosis of varicoceles[3,9,13]. US features include dilated venous plexus ( $>2-3 \mathrm{~mm}$ diameter) with serpiginous appearance posterior and lateral to the testis within the spermatic cord (Figure 8). Varicoceles increase in size on standing and show a flow reversal with valsalva maneuver; hence, scanning in the upright position and valsalva maneuver should be performed while evaluating for varicoceles[9]. 


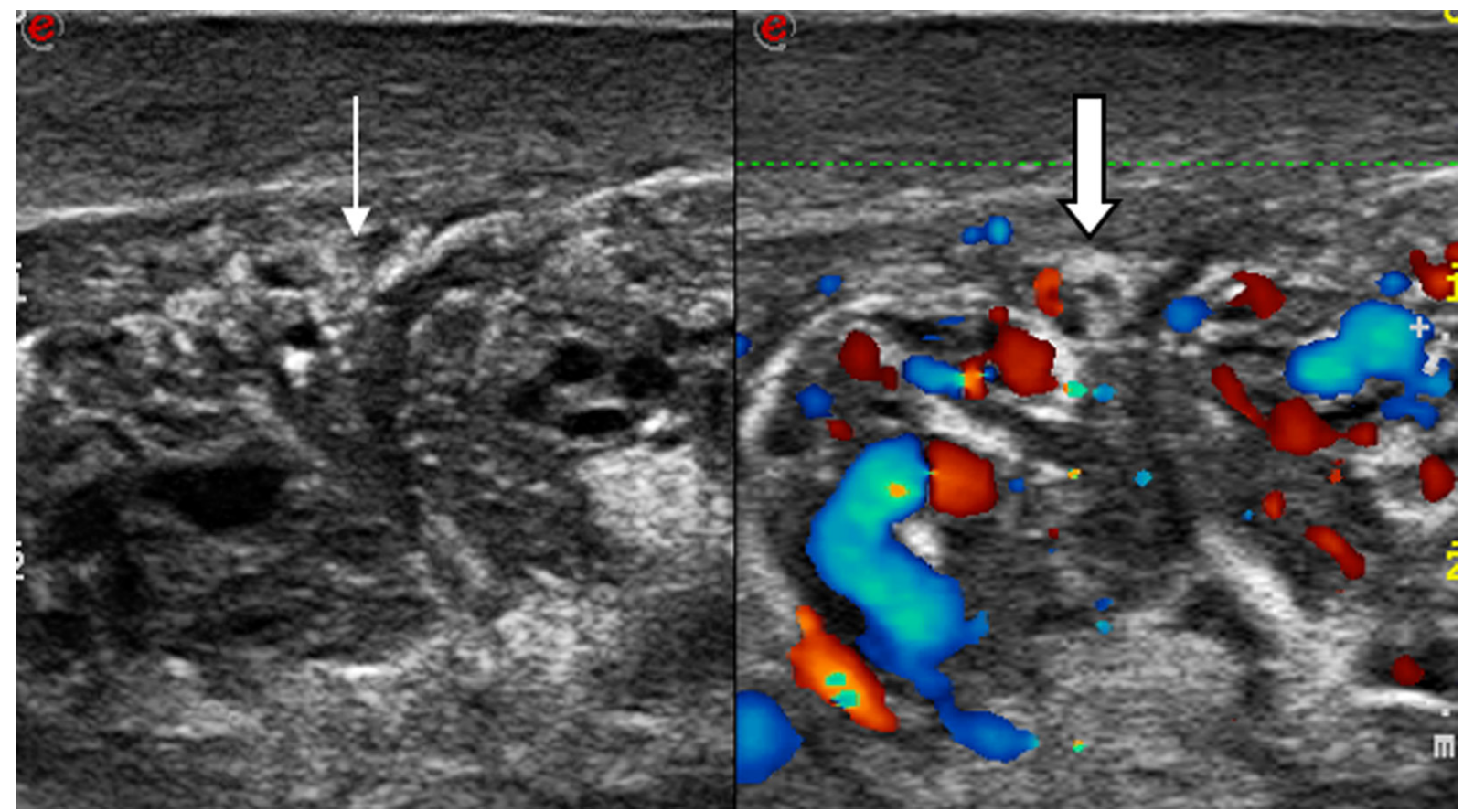

Figure 8. Varicocele: Split screen gray scale and color Doppler US show multiple tortuous, dilated veins of pampiniform plexus.

Trauma: Testicular trauma is the third most common cause of acute scrotal pain and can be blunt or penetrating[13,18]. Scrotal trauma can result in contusions, lacerations, fracture, or rupture of the testis. On US, contusions are seen as areas of heterogeneous appearance in the testis due to focal intratesticular bleeding (Figure 9A). Testicular fracture is seen as a break in the normal testis, while the testicular shape and contour are maintained (Figure 9B). Testicular rupture is seen as the discontinuity of tunica albuginea with hemorrhage and extrusion of the testicular contents into the scrotal sac (Figure 9C) $[17,18]$. Immediate surgical exploration and/or orchidectomy is needed in testicular rupture and in all the cases of scrotal trauma with impaired perfusion. Diagnostic delays or errors can lead to ischemia, infarction, necrosis and even testicular atrophy with the risk of reduced fertility and infection $[17,18]$. 


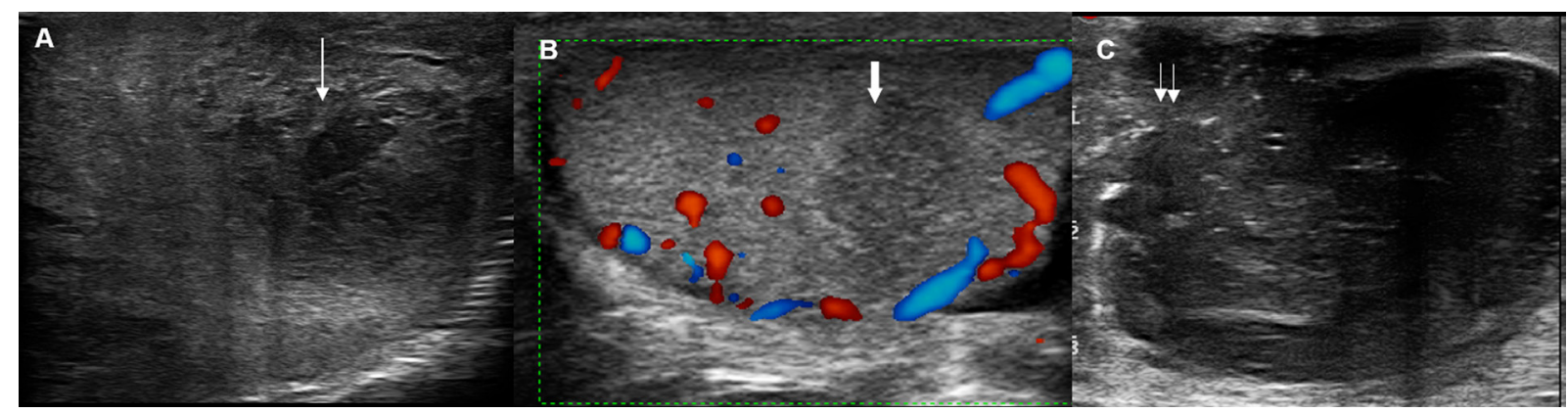

Figure 9. (A) Testicular Contusion: Focal hypoechoic, heterogenous areas in a case of blunt trauma to the testis (thin arrow). (B) Testicular fracture: Hypoechoic band extending across the testicular parenchyma (thick arrow). (C) Testicular rupture: Contour abnormality of the testis with disruption of the tunica albuginea and extrusion of testicular parenchyma through a defect in the superior pole (double arrows).

Scrotal trauma can also produce intra or extratesticular fluid collections like acute hydroceles, hematoceles, and hematomas. Hydrocele is an abnormal collection of serous fluid accumulating between the visceral and parietal layers of the tunica vaginalis. It occurs in up to $25 \%$ of all major cases of trauma and hydrocele can also be seen in acute scrotal pathologies like epididymo-orchitis, torsion and neoplasms[5]. On US, hydrocele appears as an anechoic fluid collection surrounding the anterolateral aspects of the testis. Traumatic hematoceles and hematomas occur as a collection within the tunica vaginalis or testis due to extra or intra testicular bleeding, respectively and have variable presentations on US[5]. Acute hematoceles are anechoic to echogenic (Figure 10A), whereas older hematoceles appear as a fluid collection with low-level internal echoes, fluid-fluid levels and septations $[13,18]$. Acute hematomas appear hyperechoic, and later become complex and are avascular on color Doppler (Figure 10B). 


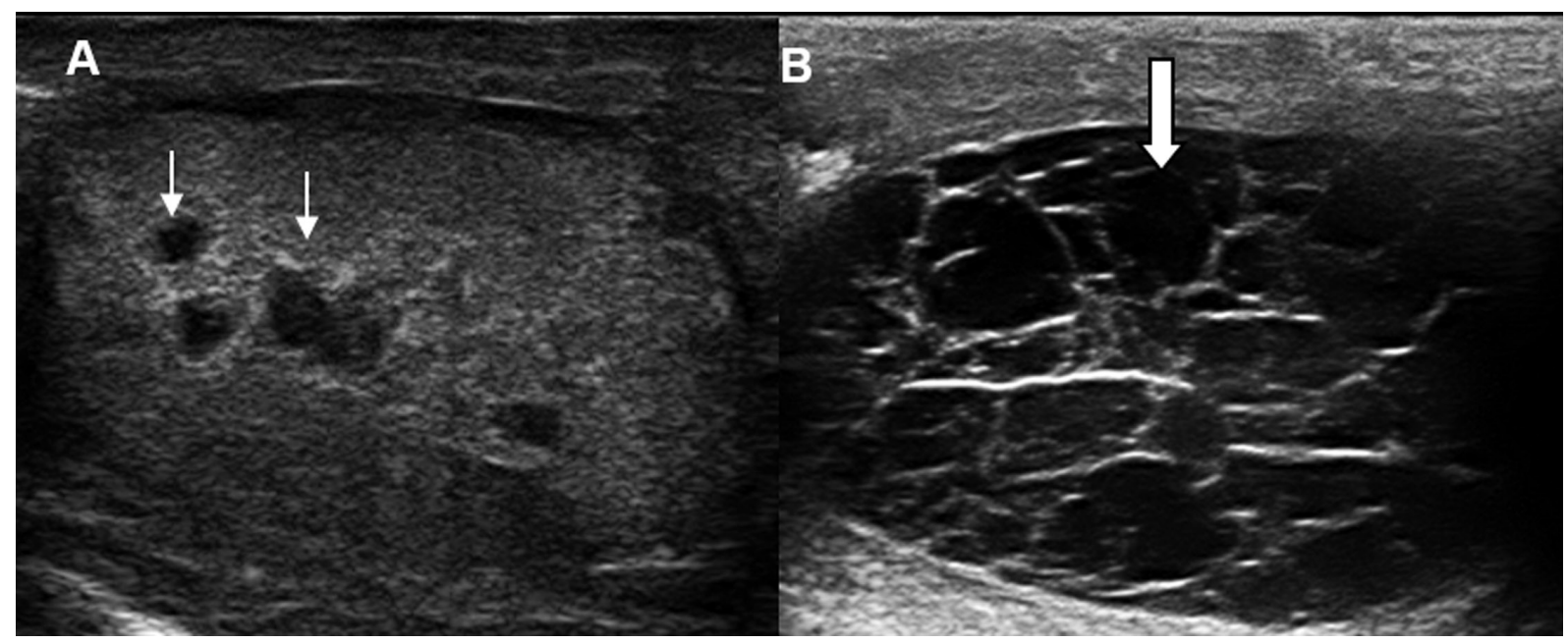

Figure 10. (A) Intratesticular hematocele: Small fluid collections seen as anechoic foci (thin arrows) within the testis in a case of blunt trauma to scrotum. (B) Intratesticular hematoma: Complex fluid collection with low-level internal echoes, fluid-fluid levels and septations seen within the testis (thick arrow) in a case of trauma.

Testicular tumors: Testicular tumors are generally painless but acute pain may occur secondary to epididymo-orchitis or aemorrhage within the tumor. US appearance of intratesticular tumors is non-specific and most tumors are homogenously hypoechoic in echotexture[19]. The commonest germ cell tumor is seminoma, and on gray-scale US, it appears as a homogeneous hypoechoic lesion (Figure 11)[13,19]. Testicular tumors may also sometimes be hyperechoic in echotexture. Nonseminomatous germ cell tumors and extratesticular tumors can be irregular with ill-defined margins and appear heterogenous in echotexture with echogenic foci due to internal calcification and hemorrhage (Figure 12)[3,19]. Testicular lymphomas can be primary or secondary nonHodgkin lymphomas, bilateral in $40 \%$ and are the most common testicular tumours after the age of $60[13,19]$. US may show a homogeneously hypoechoic testis with diffuse enlargement (Figure 13) or multiple focal hypoechoic masses[13,19]. Metastases to the testes are rare and occur most commonly from the cancers of the prostate, lung, kidney, colon, melanoma and leukaemia (Figure 14)[19]. 


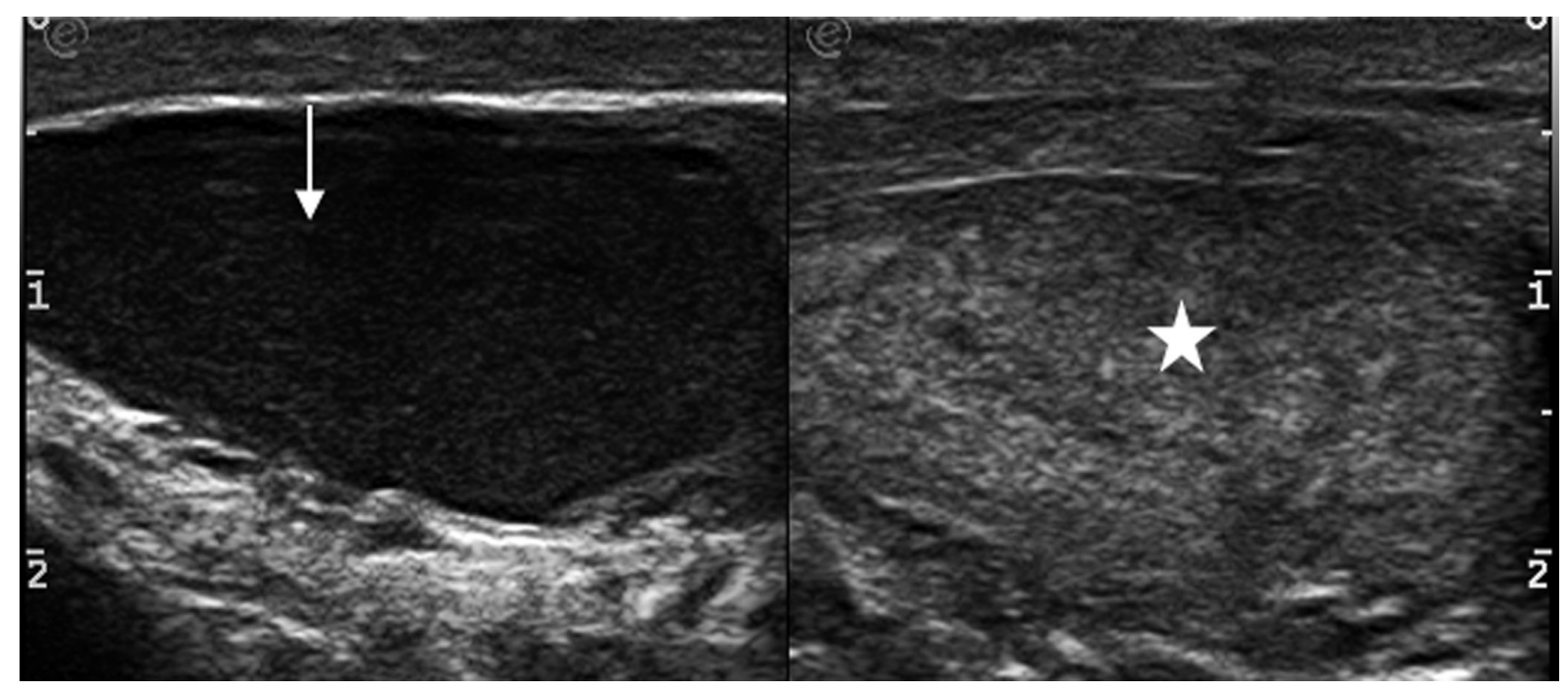

Figure 11. Seminoma: Split screen US shows diffusely hypoechoic right testis (thin arrow) compared to the normal left testis $\left(^{*}\right)$ in a case of seminoma.

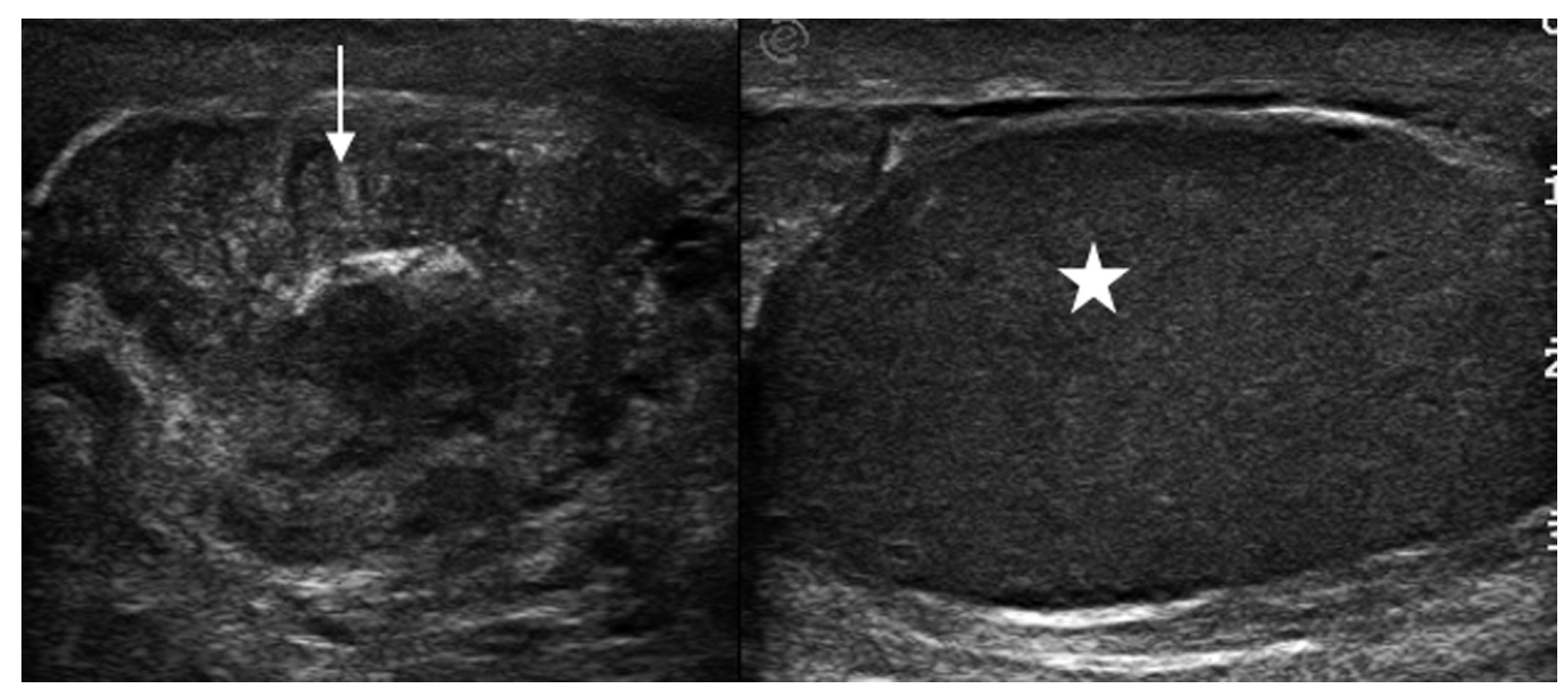

Figure 12. Germ cell tumor: Split screen US shows hypoechoic heterogenous mass with hyperechoic foci in the right testis (thin arrow) compared to the normal left testis ${ }^{*}$ ) in a case of nonseminomatous germ cell tumor of testis. 


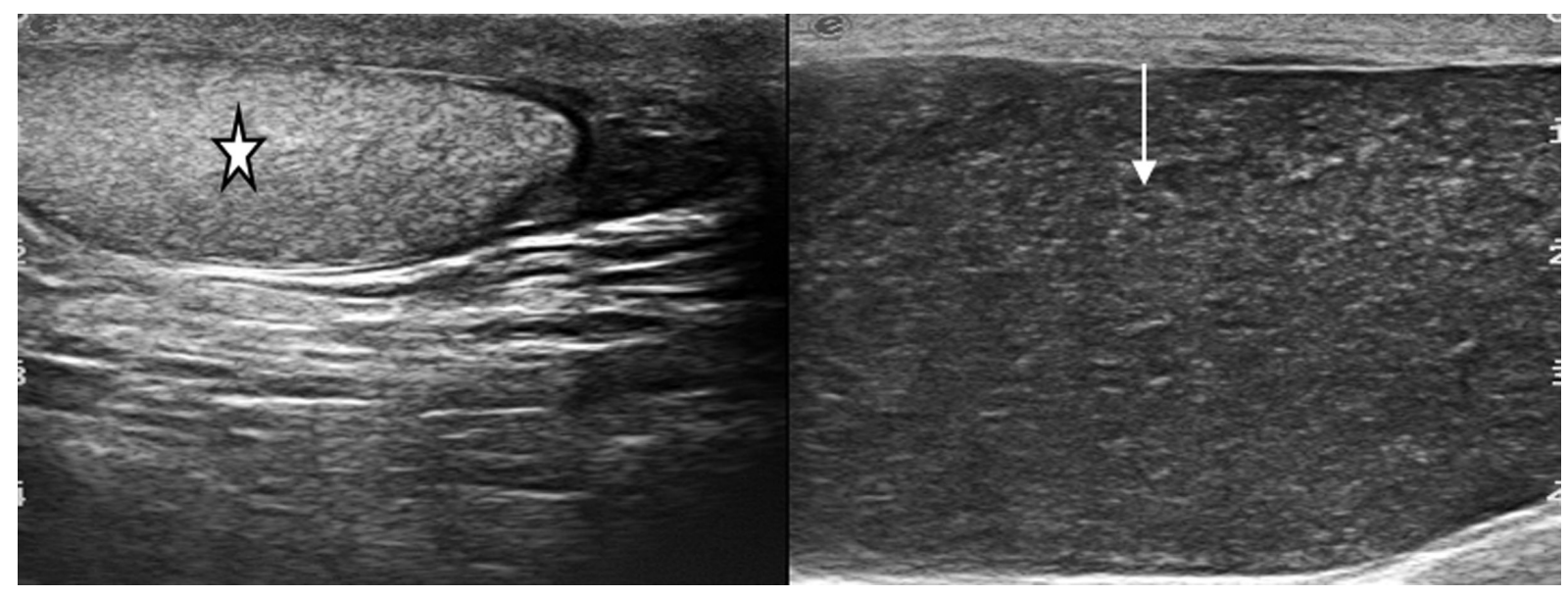

Figure 13. Lymphoma: Split screen US shows enlarged hypoechoic left testis (thin arrow) and the normal right testis $\left(^{*}\right)$ in a case of Non Hodgkin's lymphoma.

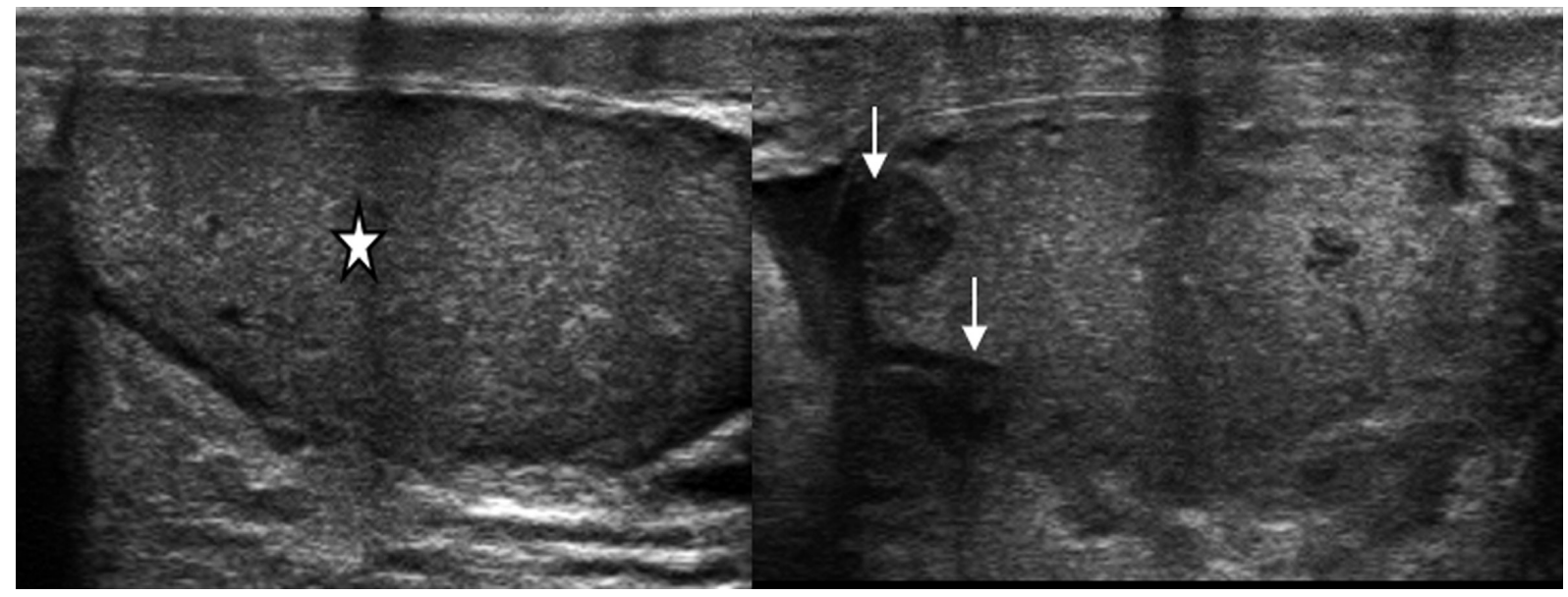

Figure 14. Leukemia: Split screen US shows small hypoechoic deposits (thin arrows) in right testis and normal left testis $\left(^{*}\right)$ in a child with leukemia. 
Miscellaneous: Inguinoscrotal hernias with incarcerated and strangulated bowel loops can present as an acute scrotum (Figure 15). A case of spermatic cord hydrocele presented as an acute scrotum was observed during our evaluation. A spermatic cord hydrocele or a cyst is a rare condition and is seen as a loculated fluid collection along the spermatic cord (Figure 16).

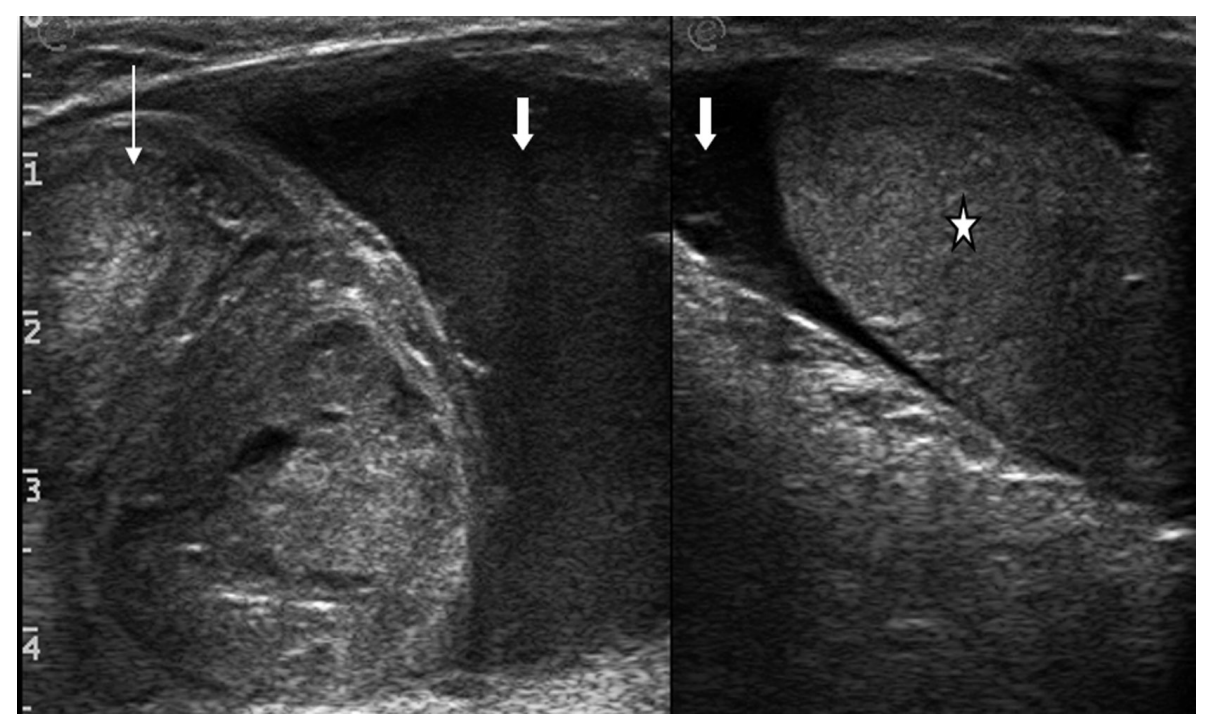

Figure 15. Intrascrotal inguinal hernia: Split screen US shows omentum and bowel loops in the scrotal sac (thin arrow), hydrocele with low level internal echoes (thick arrows) and displaced normal testis $\left({ }^{*}\right)$.

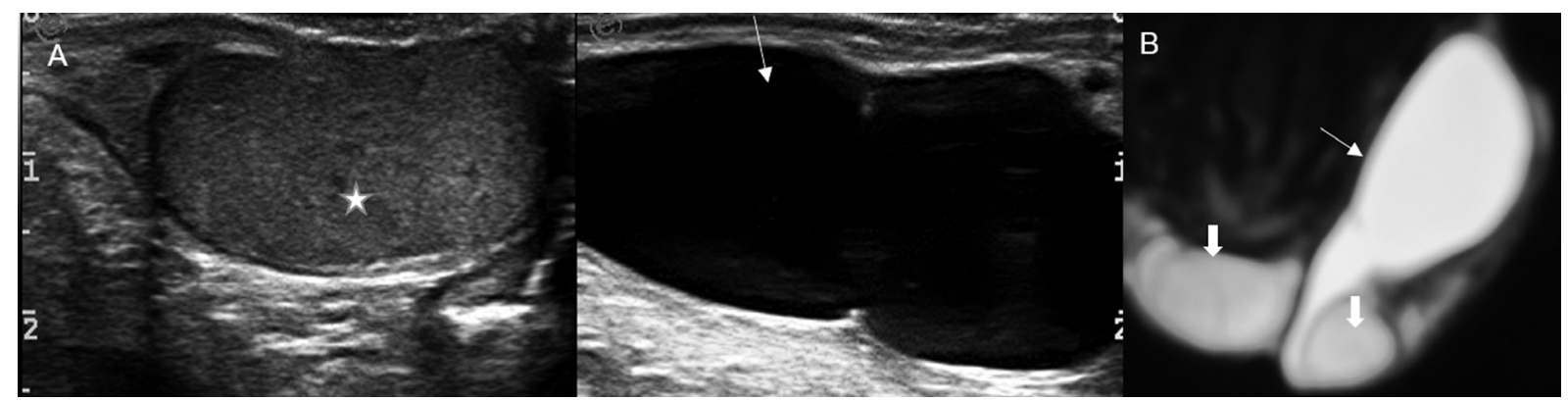

Figure 16. (A) Spermatic cord cyst: Split screen gray scale US shows the normal testis $\left({ }^{*}\right)$ and an oblong cystic lesion (thin arrow) along the course of the left spermatic cord. (B) Coronal T2W MRI image shows hyperintense left spermatic cord cyst (thin arrow) arising from the lower pole of the left testis, extending superiorly between the two normal testes (thick arrows). 
Incidental lesions in acute scrotum: A few common and uncommon lesions that are seen during the evaluation of an acute scrotum are epididymal cysts (Figure 17A), intra- or extra testicular calcifications i.e scrotoliths (Figure 17B) and testicular microlithiasis (Figure 18). They are mostly incidental findings without any clinical significance but testicular microlithiasis has a reported association with testicular neoplasia and annual US follow-up is recommended for at least several years after the diagnosis $[9,20]$.

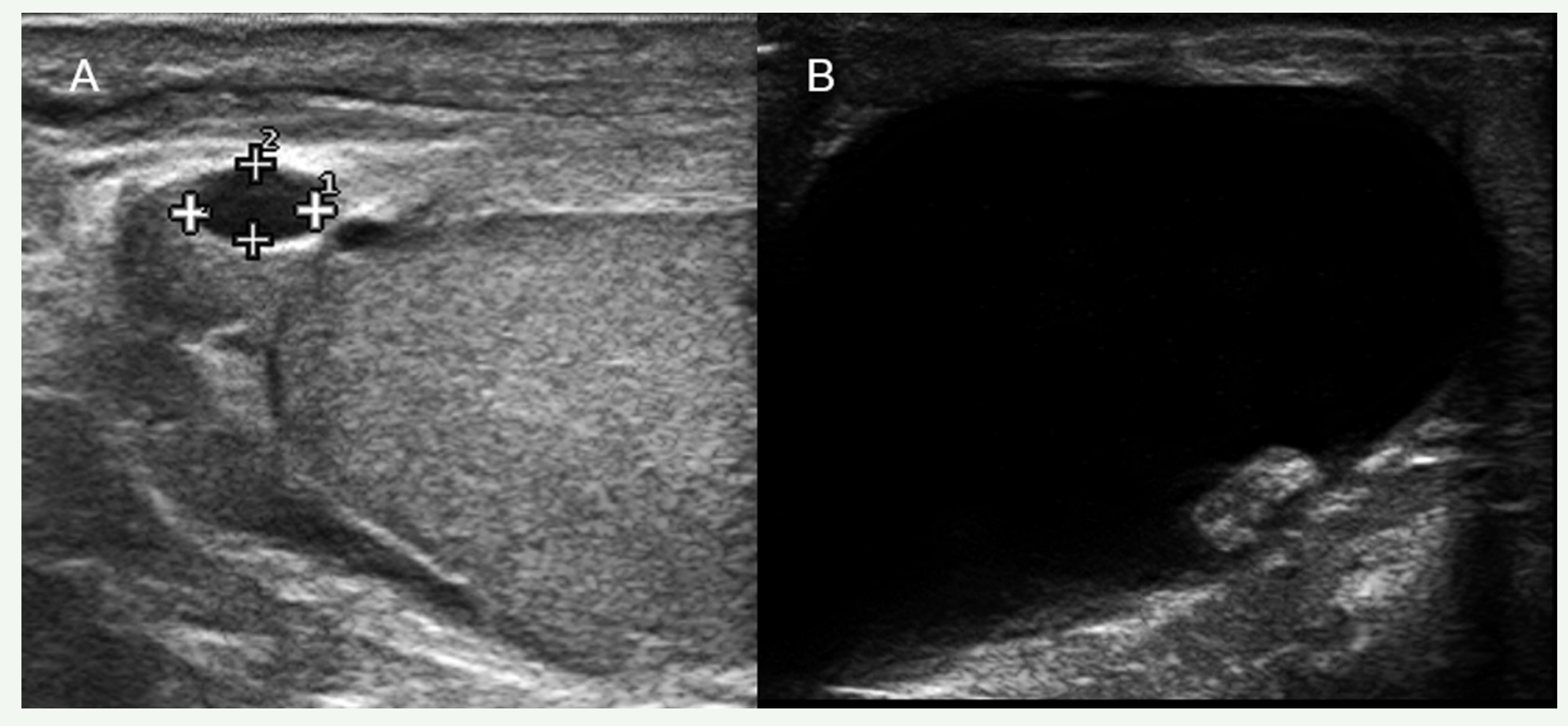

Figure 17. (A) Epididymal cyst: Well defined anechoic lesion (arrow) in the head of the epididymis. (B) Scrotolith or scrotal pearl: Extra testicular macro-calcification within the scrotum (arrow). 


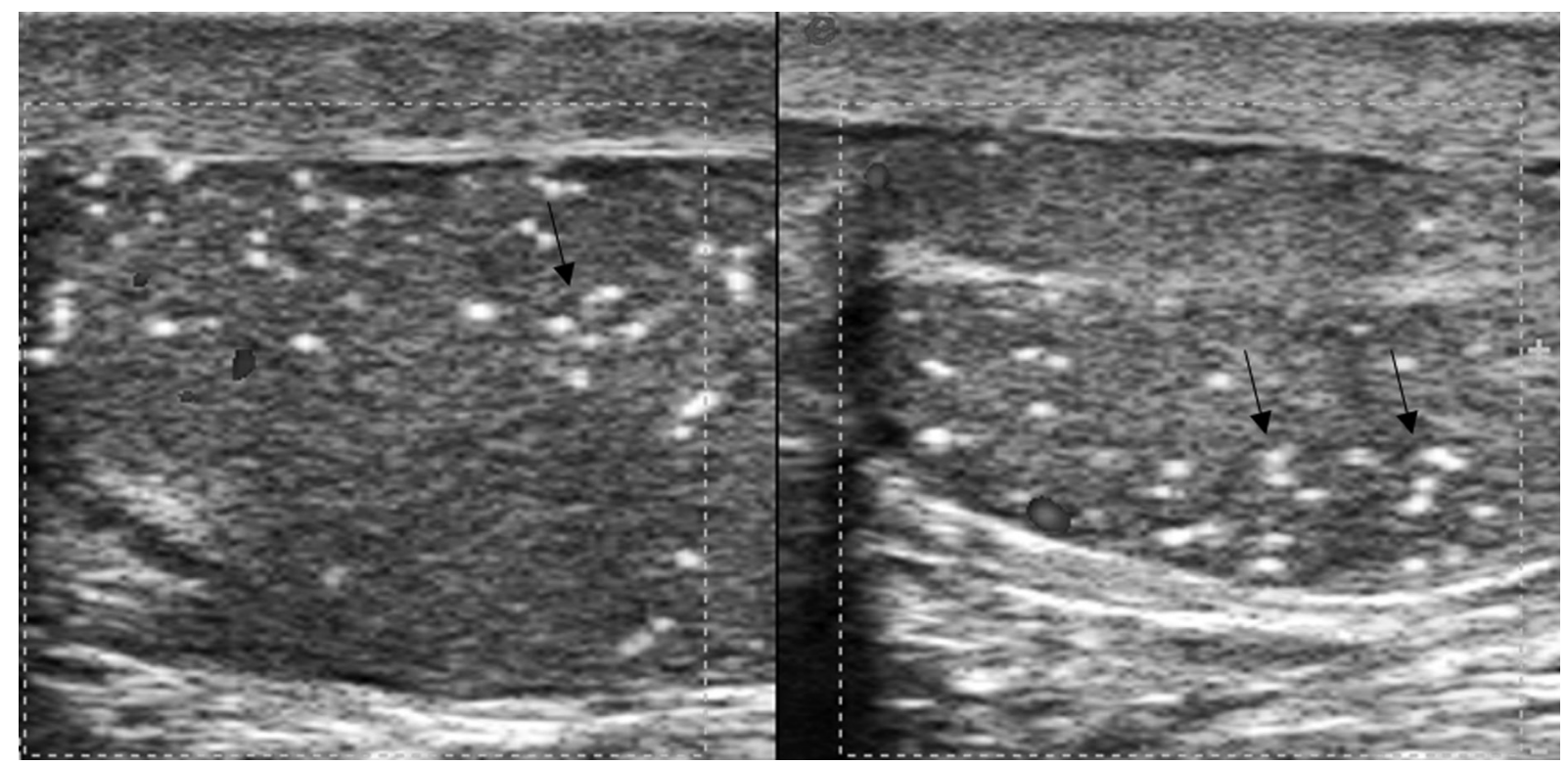

Figure 18. Testicular microlithiasis: Multiple 2-3 $\mathrm{mm}$ nonshadowing echogenic foci seen in the testis (arrows).

\section{Conclusion}

The correlation of ultrasound findings with appropriate clinical history and background can give accurate diagnosis in cases presenting with an acutely painful scrotum. In an emergency setting, US enables us to differentiate surgical emergencies like testicular torsion, scrotal abscess from acute nonsurgical causes like epididymo-orchitis. Familiarity with the imaging features of each entity including incidental lesions can avoid diagnostic errors that can significantly alter the management and outcome. 


\section{References}

1. McAndrew HF, Pemberton R, Kikiros CS, Gollow I. The incidence and investigation of acute scrotal problems in children. Pediatr Surg Int 2002;18:435-7. doi: 10.1007/s00383-002-0806-3.

2. Günther P, Rübben I. The acute scrotum in childhood and adolescence. Dtsch Arztebl Int 2012;109:449-57;quiz 458. doi: 10.3238/arztebl.2012.0449.

3. Patiala B. Role of color doppler in scrotal lesions. Indian J Radiol Imaging 2009;19:187-90. doi: 10.4103/0971-3026.54874.

4. Avery LL, Scheinfeld MH. Imaging of penile and scrotal emergencies. Radiographics 2013;33:721-40. doi: 10.1148/rg.333125158.

5. Resende DAQP, Souza LRMF, Monteiro IO, Caldas MHS. Scrotal collections: pictorial essay correlating sonographic with magnetic resonance imaging findings. Radiol Bras 2014;47:43-8.

6. Vijayaraghavan SB. Sonographic differential diagnosis of acute scrotum: real-time whirlpool sign, a key sign of torsion. J Ultrasound Med 2006;25:56374. doi: 10.7863/jum.2006.25.5.563.

7. Ragheb D, Higgins JL Jr. Ultrasonography of the scrotum: technique, anatomy, and pathologic entities. J Ultrasound Med 2002;21:171-85. doi: 10.7863/jum.2002.21.2.171.

8. Guideline developed in collaboration with the American College of Radiology; Society for Pediatric Radiology; Society of Radiologists in Ultrasound. AIUM practice guideline for the performance of scrotal ultrasound examinations. J Ultrasound Med 2015;34:1-5. doi: 10.7863/ul tra.34.8.15.13.0006. 
9. Dogra VS, Bhatt S, Rubens DJ. Sonographic evaluation of testicular torsion. Ultrasound Clin 2006;1:55-66. doi: 10.1016/j.cult.2005.09.006.

10. Dogra VS, Gottlieb RH, Oka M, Rubens DJ. Sonography of the scrotum. Ra diology 2003;227:18-36. doi: 10.1148/radiol.2271001744.

11. Doherty, FJ. Ultrasound of the nonacute scrotum. Semin Ultrasound CT MR 1991;12:131-56.

12. Healy JC. Spermatic cords and scrotum. In: Standring S, editor. Gray's anatomy: the anatomical basis of clinical practice. 39th ed. Edinburgh: Chur chill Livingstone; 2005. p.1313-4.

13. Bhaskar MV, Pramod JS. Pictorial essay of high resolution and colour doppler sonography of scrotal pathologies. The Internet Journal of Radiology [Internet] 2009[cited 2020 Jan 2 ];12(2):[about 15 p.]. Avalable from: https:// print.ispub.com/api/0/ispub-article/13505.

14. Castleberg E, Jenson N, Dinh VA. Diagnosis of necrotizing faciitis with bed side ultrasound: the STAFF exam. West J Emerg Med 2014;15:111-3. doi: 10.5811/westjem.2013.8.18303.

15. Mandava A, Rao RP, Kumar DA, Naga Prasad IS. Imaging in emphysematous epididymo-orchitis: a rare cause of acute scrotum. Indian J Radiol Imaging 2014;24:306-9. doi: 10.4103/0971-3026.137067.

16. Muttarak M, Lojanapiwat B. The painful scrotum: an ultrasonographical ap proach to diagnosis. Singapore Med J 2005;46:352-7; quiz 358.

17. Lobianco R, Regine R, De Siero M, Catalano O, Caiazzo C, Ragozzino A. Contrast-enhanced sonography in blunt scrotal trauma(). J Ultrasound 2011;14:188-95. doi: 10.1016/j.jus.2011.09.003. 
18. Deurdulian C, Mittelstaedt CA, Chong WK, Fielding JR. US of acute scrotal trauma: optimal technique, imaging findings, and management. Radiographics 2007;27:357-69. doi: 10.1148/rg.272065117.

19. Coursey Moreno C, Small WC, Camacho JC, Master V, Kokabi N, Lewis M, et al. Testicular tumors: what radiologists need to know--differential diagnosis, staging, and management. Radiographics 2015;35:400-15. doi: 10.1148/rg.352140097.

20. Bhatt S, Rubens DJ, Dogra VS. Sonography of benign intrascrotal lesions. Ultrasound Q 2006;22:121-36. doi: 10.1097/00013644-200606000-00025. side ultrasound: the STAFF exam. West J Emerg Med 2014;15:111-3. doi: 10.5811/ westjem.2013.8.18303. 